\title{
SUBJETIVIDADE E EDUCAÇÃO A PARTIR DA FILOSOFIA BERGSONIANA
}

\author{
Luka de Carvalho Gusmão* \\ Sandrelena da Silva Monteiro* \\ Tarcísio Jorge Santos Pinto*
}

Resumo: Bergson concebeu sua teoria do conhecimento fundamentada numa teoria da vida: com base nos dados da experiência, defende que a vida desenvolve potenciais de consciência, liberdade, inteligência e intuição que culminam no ser humano. Neste artigo, após contextualizarmos sua vida e obra, buscamos mostrar como, a partir de sua teoria do conhecimento, delineia-se uma forma inovadora de se compreender a subjetividade e a educação.

Palauras-chave: Henri Bergson. Evolução criadora. Subjetividade. Educação. Bom senso.

Resumen: Bergson concibió su teoría del conocimiento basada en una teoría de la vida: sobre la base de los datos de la experiencia, sostiene que se la vida desarrolla potencial de la conciencia, la libertad, la inteligencia y la intuición que culminan en los seres humanos. En este artículo, después de contextualizar su vida y obra, tratamos de mostrar cómo, a partir de su teoría del conocimiento, se perfila una forma innovadora de entender la subjetividad y la educación.

Palabras claves: Henri Bergson. Evolución creativa. Subjetividad. Educación. Bueno sentido.

\footnotetext{
" Universidade Federal de Juiz de Fora. Emails: lukagusmao87@yahoo.com.br; sandrelenasilva@yahoo.com.br; tarcisio.pinto@ufff.edu.br
}

\section{Vida e obra de Henri Bergson}

Em 18 de outubro de 1859, nasceu na França, Henri Louis Bergson, um pensador contemporâneo que contribuiu significativamente para a filosofia e a ciência de nossa época.

Logo em seus estudos iniciais, o jovem Bergson se destacou como aluno brilhante nas Letras, nas Ciências e na Matemática, conforme esclarece Vieillard-Baron (2007). Posteriormente a esses estudos, no ano de 1878, ingressou na Escola Normal Superior no setor de Letras, mostrando, ao mesmo tempo, grande interesse pela Filosofia. Em 1881 foi designado professor no Liceu de Angers e dois anos depois em ClermontFerrand. Neste período, de acordo com Pessanha (1979), Bergson publicou Extraits de Lucrèce, trabalho no qual abordou tanto o tratamento que devemos dar ao estudo da História da Filosofia quanto uma crítica ao determinismo (COELHO, 2003).

Imbuído do desejo de se dedicar à filosofia das ciências e afastando-se do pensamento de Kant, Berg-

GUSMÃO, Luka de Carvalho; MONTEIRO, Sandrelena da Silva; PINTO, Tarcísio Jorge Santos. A tradição na experiência filosófica nietzschiana. Revista SulAmericana de Filosofia e Educação. Número 22: mai-out/2014, p. 90-107. 
son empreendeu o estudo da doutrina de Herbert Spencer ${ }^{1}$. O filósofo francês acreditou ter encontrado no pensamento spenceriano uma nova perspectiva filosófica que, em última análise, estaria ancorada na experiência da natureza e nos dados da ciência. Para ele a aproximação da filosofia com a biologia tornaria a realidade mais manifesta do que se fundamentada na matemática e na física. Considerando, todavia, que certos princípios do pensamento de Spencer estavam ainda incipientes, Bergson (1979) propôs-se completá-los e consolidá-los. Ao chegar à ideia de tempo que lhes era subjacente percebeu que as conclusões spencerianas acerca da evolução se fundamentavam na noção de tempo da ciência mecânica e não no tempo real e concreto da vida, que Bergson intui como "duração". Em razão disso, passou de um estudo inicial para uma postura crítica e emancipatória em relação à filosofia de Spencer. Bergson (1979) acreditava que teríamos a experiência direta da duração em nossa própria consci-

\footnotetext{
${ }^{1}$ Filósofo inglês nascido em Derby em 1820 e morto em Brighton em 1903, responsável por uma vasta produção na qual as ciências da vida passaram a ser referências básicas $e$ onde a ideia de evolução ocupou papel central.
}

ência e que, através do seu estudo, poderíamos, em última análise, por meio da psicologia, iniciar o estudo da metafísica, campo ao qual a partir de então procurou se dedicar.

No ano de 1888 , defendeu suas duas teses de doutorado, sendo que a primeira continha um estudo sobre a concepção de lugar em Aristóteles (Quid Aristoteles de Loco Senserit) e a segunda, chamada Essai sur les données immédiates de la conscience, o desenvolvimento da noção de duração em relação à vida psicológica. No horizonte do Essai, Bergson estabeleceu uma crítica às concepções filosóficas e científicas que partem de uma noção errônea da interioridade humana e concluiu, consequentemente, que as teorias que tendem a explicá-la em função do espaço acabam por descaracterizá-la ao representá-la em termos mecânicos e deterministas. Para ele a liberdade da consciência humana apareceria como um "fato indubitável".

Mesmo trabalhando intensamente como professor Bergson não interrompeu sua produção filosófica após o término de suas primeiras obras e empreendeu o exame da experiência relativa à consciência huNúmero 22: maio - outubro/2014 
mana em sua relação com a realidade material na qual está inserida. Passou a investigar a liberdade do espírito em sua relação concreta com o mundo, e, no ano de 1897, publicou Matière et mémoire - Essai sur la relation du corps et de l'esprit, onde concluiu que a duração estaria também associada ao universo material.

No ano de 1900, assumiu uma cátedra de Filosofia no Colégio de França, ao mesmo tempo em que foi eleito membro da Acadêmica das Ciências Morais e Políticas (VIEILLARDBARON, 2007). Neste período suas obras atingiram um grande reconhecimento, fazendo com que suas aulas estivessem sempre repletas de estudantes interessados no estudo de sua filosofia.

Suas conferências no 'Collège de France' eram verdadeiras obras de arte, arrebatando auditórios superlotados, onde ouvia-se, frequentemente, o murmúrio da admiração e do encanto. Por isso, chamavamno de joueur de flute, o tocador de flauta, pois a todos hipnotizava com o timbre aflautado de sua voz, o discurso de um mestre espiritual e a retórica de um orador clássico (TREVISAN, 1995, p. 15).
Dando continuidade à sua produção intelectual, o filósofo francês publicou Le Rire - Essai sur la signification $d u$ comique composto por três artigos que havia divulgado anteriormente.

Pessanha (1979) informa que nos primeiros anos do século XX, Bergson conheceu o psicólogo e filósofo norte-americano Willian James, com quem desenvolveu, apesar de certas diferenças filosóficas, uma sólida amizade, que ficou expressa nas cartas com as quais se correspondiam. Neste período, mais precisamente no ano de 1907, Bergson publicou a obra de maior destaque em seu pensamento e que, de acordo com Morato Pinto, Borba e Kohan (2007), revelou-se o trabalho de filosofia mais estudado na primeira metade do século XX: L'Évolution créatice. O evolucionismo concebido até a segunda metade do século XIX tinha um viés materialista, ao qual Bergson responde com uma concepção espiritualista (PESSANHA, 1979). É nesta obra que ele pôde unir finalmente, teoria do conhecimento e teoria da vida, evidenciando como a evolução da vida se processa em íntima relação com a evolução das formas de conhecimento na natureza. A edição desta última obra fez aumentar seu Número 22: maio - outubro/2014 
prestígio, levando-o a uma intensa produção intelectual através da participação em congressos e da publicação de trabalhos em diversas revistas, especialmente a Revue de Métaphysique et Morale, Revue Philosophique, Vocabulaire Philosophique, entre outras publicações francesas e estrangeiras.

Nos anos seguintes, Bergson fez algumas viagens com o objetivo de proferir cursos e conferências, entre eles um curso sobre espiritualidade e liberdade, ministrado em 1912 nos EUA. Contudo, no ano de 1914, em função de problemas de saúde, afastou-se temporariamente de sua cátedra no Colégio de França, da qual viria a se retirar definitivamente em 1921. Mesmo abalado em suas forças, escreve Pessanha (1979) que Bergson não se colocou à margem dos acontecimentos políticos de sua época, atuando em missões diplomáticas na Espanha e nos EUA. Ele estava convencido, de acordo com informações de Vieillard-Baron (2007), de que o filósofo deveria trabalhar pela edificação da paz. O ano de 1914 assinalou, além dos acontecimentos acima descritos, o ingresso de Bergson na Academia Francesa, uma instituição criada no ano de 1635, formada por quarenta indivíduos de grande destaque no cenário intelectual do país que vão se alternando ao longo do tempo. Ao fim de 1919, o filósofo francês passou a colaborar na Sociedade das Nações - entidade que deu origem à UNESCO - presidindo a Comissão de Cooperação Intelectual.

Também no ano de 1919, Bergson publicou L'Énergie spirituelle, obra composta por escritos cujos temas perpassaram a consciência e a vida, a relação entre corpo e alma, o sonho, a relação entre cérebro e pensamento. Logo em seguida, em 1922, apresentou-nos Durée et simultaneité onde, segundo Pessanha (1979) e Vieillard-Baron (2007), revelou as reflexões que realizou acerca das teorias de Albert Einstein sobre a relatividade e os tempos múltiplos. Apesar do agravamento das dificuldades de saúde que enfrentava, o pensador francês continuou seu trabalho. Em 1932, publicou Les Deux sources de la morale et de la religion, obra na qual desdobrou sua concepção de duração em relação ao desenvolvimento moral e religioso, "defendendo que, com base em uma intuição espe- 
cial, a 'intuição mística' (l'intuition mystique) da duração da vida, algumas grandes personalidades são capazes de realizar uma renovação ética e religiosa que pode nos servir de ideal" (SANTOS PINTO, p. 13). Dois anos mais tarde, Bergson publicou La Pensée et le mouvant, coletânea de conferências e textos que, de certa forma, sintetizavam sua filosofia. Estes dois últimos livros confirmaram a admiração em torno de seu pensamento, mas, efetivamente, seu prestígio já havia sido consolidado desde 1928, ano em que ganhou o prêmio Nobel de Literatura.

Bergson morreu no ano de 1941. Pessanha (1979) afirma que o pensador francês, embora de origem judia, manifestou aproximação crescente ao cristianismo no fim de sua vida, mas não se converteu, pois não queria abandonar seu povo no período da perseguição nazista. Embora tenha enfrentado sérias dificuldades na realização de seu trabalho, o filósofo francês não deixou de acreditar na vitória do espírito sobre a matéria, do impulso vital sobre a inércia, do trabalho sobre a preguiça (VIEILLARD-BARON, 2007).

\section{A noção de subjetividade em Bergson - repercussões na educação}

Acertadamente, não há como pensar em uma educação futurista, pois que, se não há como préestabelecer o futuro, também não será possível prever que necessidades surgirão e muito menos que atitudes deverão ser tomadas no sentido de suprir tais necessidades. Pensar uma educação que desenvolva a liberdade do ser humano, sua iniciativa e criatividade, tal qual proposta por Bergson, implica também situar que concepção de subjetividade fundamenta tal proposta pedagógica.

A concepção de subjetividade em Bergson será formada a partir do seu entendimento acerca da própria vida, e, para este filósofo, vida é criação. Neste sentido, o sujeito, produto e produtor desta vida também é um processo de criação contínua: uma complexa evolução criadora (BERGSON, 2005).

Na perspectiva de uma evolução criadora da vida, torpor vegetati$v o$, instinto e inteligência coincidem na impulsão vital comum às plantas $e$ aos animais, e se dissociam nas formas mais imprevistas pelo simples 
fato de seu crescimento. Constituem assim "três direções divergentes de uma atividade que se cindiu ao crescer. A diferença entre elas não é uma diferença de intensidade, nem, de modo mais geral, de grau, mas de natureza" (BERGSON, 2005, p. 147, grifo do autor). Nesse processo, "instinto" e "inteligência" são duas vias divergentes sobre as quais a evolução do reino animal se efetua, culminando uma no inseto e a outra no homem. Instinto e inteligência se opõem e se complementam. Não existe, portanto, entre eles uma relação de hierarquia evolutiva, há aí uma diferença de natureza e não de grau. Tendo desde o início se interpenetrado, conservam algo de sua origem comum e não são encontrados em estado puro. Encontrá-los-emos sempre misturados, diferindo, no entanto, a proporção em uma ou outra situação. Instinto e inteligência são tendências e não estados ou coisas prontas e acabadas. São duas formas diferentes de atividade psíquica, de ação sobre a matéria inerte e é a diversidade desse esforço de atuação que os diferencia. (BERGSON, 2005).

Tudo se passa como se a força imanente à vida, sendo limitada $e$ não podendo realizar-se ao mesmo tempo em várias direções, tivesse que fazer a escolha entre duas maneiras de agir sobre a matéria bruta: a ação "imediata", imanente a seu próprio movimento, cuja essência é utilizar e fabricar instrumentos "organizados", naturais; ou a ação "mediatizada", própria ao organismo que, não possuindo naturalmente o instrumento necessário à sua sobrevivência, fabrica e utiliza instrumentos artificiais. É nesse sentido que o homem poderia ser definido como "homo faber" ao fabricar, de forma a suplantar sua insuficiência natural, meios e instrumentos de se adaptar à vida e suas condições existenciais. Aqui já se compreende que instinto $e$ inteligência representam duas soluções divergentes para um único problema: a adaptação à vida. São, desse modo, duas formas diferentes de conhecimento.

Um outro fator de diferenciação entre instinto e inteligência se dá pela presença, em suas ações, da consciência, consciência que "é a luz imanente à zona de ações possíveis ou de atividade virtual que cerca a ação efetivamente realizada pelo ser vivo. Significa hesitação ou escolha" Número 22: maio - outubro/2014 
(BERGSON, 2005, p. 157). Haverá consciência em maior intensidade onde houver ações igualmente possíveis que se desenham, sem, no entanto, haver nenhuma ação real já concretizada. Ao contrário, onde uma ação real é a única possível, a consciência torna-se nula. Assim, consciência significa ação que pressupõe, precisamente, sua escolha. "Pois que a consciência corresponde exatamente à potência de escolha de que o ser vivo dispõe; é co-extensiva à franja de ação possível que envolve a ação real: consciência é sinônimo de invenção e de liberdade" (BERGSON, 2005, p. 286).

A consciência é coextensiva à vida, segundo Bergson (2009). Daí se entende que todo ser vivo é mais ou menos consciente. Outrossim, Bergson relaciona consciência à escolha, afirmando que o papel da consciência é decidir-se. Portanto, em organismos que não se movem espontaneamente e que não têm que tomar decisões, é duvidoso que se encontre consciência. Mas Bergson ressalta que não há ser vivo que seja totalmente incapaz de se movimentar de forma espontânea, o que acontece, a seu ver, é que alguns renunciam a esta capacidade.
Da mesma forma, renunciam à consciência e à escolha. Esta é, por exemplo, a situação dos vegetais, parasitas da terra, e de alguns animais que vivem como parasitas de outros. Bergson entende, desta forma, que a consciência, originalmente imanente a tudo que vive, atenua-se onde o movimento é escasso. Na relação entre consciência e escolha, afirma que, quando uma de nossas ações deixa de ser consciente e passa a ser automática, a consciência retira-se da ação (BERGSON, 2006).

Mas se consciência é escolha, está vinculada também à invenção $e$ à liberdade. Tomando a invenção como referência, veremos que nos animais em geral esta se limita aos automatismos dos hábitos da espécie. Já no homem, o automatismo é interrompido, surgindo o dado da invenção, da fabricação de instrumentos para a ação. Isso se deve, também, ao desenvolvimento da inteligência, que tem como função a adaptação do ser humano ao mundo material.

Nesse processo evolutivo, há conflitos e aparentes contradições, uma vez que, ao buscar a adaptação à matéria, a inteligência, que tem sua atividade orientada para a fabricação, Número 22: maio - outubro/2014 
trata a matéria organizada como um conjunto de objetos inertes: não considera a vida que os formou; desconsidera exatamente aquilo que é fluido, móvel; imobiliza para conhecer. Assim, ao agir sobre a matéria extensa, a inteligência trata cada objeto como passível de ser fragmentado arbitrariamente $e$ indefinidamente, de ser dividido em partes e unidades isoladas e independentes umas das outras. Destaca Bergson (2009) que, nesta forma de conhecer, a inteligência só representa claramente o que é descontínuo e imóvel. E buscando conhecer aquilo que escapa à matéria bruta, a inteligência acabou por fazer uso dos mesmos instrumentos e métodos: assim, acabou por perpetuar a tendência de imobilizar aquilo que era móvel. Esta atividade da inteligência no ato de conhecer certamente explica sua inaptidão para, sozinha, compreender a essência da vida e a significação profunda do movimento evolutivo da criação. Por mais que tente explicar por suas representações conceituais o devir, este lhe escapará, pois é mobilidade, movimento contínuo. $\mathrm{E}$ isto acontece porque a inteligência continua aplicando no campo da reflexão especulativa o mesmo esquema espacial que utiliza para instrumentalizar sua ação sobre a matéria.

Entretanto, ao lado da inteligência, desenvolveu-se também o instinto, e, enquanto a primeira trata todas as coisas mecanicamente, o segundo as trata de forma orgânica. Explica Bergson (2005, p. 179) que se "a consciência que nele dormita despertasse, caso ele se interiorizasse em conhecimento em vez de se exteriorizar em ação, caso soubéssemos interrogá-lo e caso ele pudesse responder, o instinto haveria de nos franquear os mais íntimos segredos da vida". Ora, se não "há inteligência ali onde não se descobrem vestígios de instinto, não há instinto, sobretudo, que não esteja envolto por uma franja de inteligência" (BERGSON, 2005, p. 147). E, se o instinto pode me dar acesso àquilo que a inteligência não consegue conhecer, talvez haja uma possibilidade de encontro entre ambos. É o que nos propõe Bergson: o acesso ao conhecimento por uma via inteiramente diferente, a da simpatia, proporcionada pela "intuição", o "instinto tornado desinteressado, consciente de si mesmo, capaz de 
refletir sobre seu objeto e de ampliá-lo indefinidamente" (p. 191).

$\mathrm{Na}$ sociedade atual a intuição acabou por ceder quase todo espaço à inteligência. Isso se deu devido à necessidade do ser humano de adaptar-se aos hábitos do mundo material e concentrar toda a sua atenção nele para, a partir daí, poder desenvolver a ciência e a vida social. Somente indo além da matéria poderá a inteligência "recolher-se para dentro $e$ despertar as virtualidades de intuição que nela ainda dormitam" (BERGSON, 2005, p. 197), possibilitando, desta forma, chegar a um modo de conhecer que nos dá um acesso mais profundo à vida espiritual. É pela intuição que a filosofia nos introduz propriamente na vida, e, "mostra-nos ao mesmo tempo, a relação da vida do espírito com a do corpo", e ainda que fracasse "caso não se decida a ver a vida do corpo ali onde realmente está, no caminho que leva à vida do espírito" (p. 290-291). Com este entendimento Bergson anuncia o que ficou por muito tempo apenas no campo do misticismo religioso: a vida do corpo e a vida do espírito, e, ainda, a relação entre ambos que, em seu conjunto, formará a existência do ser.

Quando Bergson fala da relação entre corpo e espírito, explicita, sem sombra de dúvidas, sua crença na existência de algo mais no ser humano que somente seu corpo biológico ou aquilo que pode ser aprisionado pelos conceitos científicos de sua época. Abre assim a possibilidade para pensarmos o ser humano em uma outra e complexa relação com a própria vida. Por toda sua obra é nítido o movimento de retomada da discussão sobre o espírito enquanto liberdade criadora. Ao refletir sobre a existência do espírito, na conferência A Alma e o Corpo, Bergson afirma que

[...] ao lado do corpo que está confinado no momento presente do tempo e limitado ao lugar que ocupa no espaço, que se comporta como autômato e reage mecanicamente às influências externas, captamos algo que se estende muito além do corpo no espaço e que perdura ao longo do tempo, algo que pede ou impõe ao corpo movimentos não mais automáticos e previstos, $e$ sim imprevisíveis e livres: esse algo que transborda do corpo por todos os lados e que recriando a si mesmo cria atos é o "eu", é a "alma", é o espírito Número 22: maio - outubro/2014 
sendo o espírito precisamente uma força que pode extrair de si mesma mais do que contém, devolver mais do que recebe, dar mais do que tem (BERGSON, 2009, p. 31).

Muitas questões se fazem presentes nesta concepção bergsoniana, dentre elas a que se refere à natureza do espírito e do acesso a esta vida espiritual. Certamente, não há como, no âmbito deste trabalho, dar conta da natureza do espírito, mas de uma aproximação de um entendimento possivel a partir de seus atributos. Dentre todos, o que se destaca como o de maior importância é o que o define como um ser consciente. $\mathrm{Na}$ conferência $A$ consciência e a vida, Bergson afirma que: "quem diz espírito diz, antes de tudo, consciência" (BERGSON, 2009, p. 4). Quanto à relação entre espírito e corpo, chama a atenção para dois fatos que são bastante diferentes: um é aceitar que a vida da alma (espírito) ou a vida da consciência (como prefere a ciência) está ligada à vida do corpo, ou seja, que haja solidariedade entre elas; isto ele não contesta. Outro, muito diferente é afirmar que o cerebral é equivalente ao mental, que se poderia ler no corpo tudo o que acontece na consciência correspondente. Em relação a isto afirma que é certo que existem relações, uma solidariedade entre a consciência e o cérebro; no entanto, isto não resulta em que o cérebro desenhe todos os detalhes da consciência, ou ainda que seja sua causa. Com este entendimento, tudo o que se pode afirmar é que existe uma certa relação entre um $e$ outro $e$ não uma necessária e única relação de causa e efeito. "Assim sendo, digolhes que um exame atento da vida do espírito e de seu acompanhamento fisiológico me leva a crer que o senso comum tem razão e que há infinitamente mais numa consciência humana do que no cérebro correspondente" (BERGSON, 2009, p. 41). Bergson se adianta à sua época, afirmando que se a ciência pudesse enxergar o interior de um cérebro em plena atividade, com certeza ficaria conhecendo alguma coisa do que acontece no espírito, todavia conheceria apenas uma parte da vida espiritual. "Conheceria tão somente o que é exprimível em gestos, atitudes e movimentos do corpo, o que o estado de alma contém de ação em vias de realização ou simplesmente nascente; o 
restante lhe escaparia" (BERGSON, 2009, p. 42).

Considerando a existência do espírito enquanto algo que transborda ao corpo, mas que está em relação com ele, Bergson (2009) afirma que cérebro e pensamento constituem uma relação complexa e sutil, uma vez que o pensamento está direcionado para a ação e que, quando esta não se realiza, "esboça uma ou mais ações virtuais, simplesmente possíveis" (p. 46). A estas ações, reais ou virtuais, que são projeções diminutas do pensamento no espaço e marcam suas articulações motoras, correspondem desenhos na substância cerebral que são atualmente registrados, por exemplo, através de avançados processos da neurociência. No entanto, não se pode afirmar que tudo o que ocorre no espírito seja registrado no cérebro pela ação do pensamento. A partir de um estudo minucioso, Bergson chegou ao entendimento de que mesmo que não se tenha chegado à chave da relação entre espírito e corpo, pelo menos foi possivel compreender que o cérebro seria "um órgão de pantomima e tão somente de pantomima" (BERGSON, 2009, p.46). Ou seja, seu papel seria o de "imitar a vida do espírito, imitar também as situações externas a que o espírito deve adaptar-se" (p.46-47). O cérebro, na medida em que extrai da vida do espírito tudo o que ela tem de executável em movimento e materializável, constitui "o ponto de inserção do espírito na matéria" (p. 47), garantindo, assim, a adaptação mútua de ambos. O cérebro mantém ininterruptamente o espírito em contato com a realidade material já que é um órgão de "atenção à vida" e não a sede da vida.

Diante destas breves considerações acerca do ser humano tendo como suporte a filosofia bergsoniana, já o podemos entrever enquanto um ser inteligente, consciente e intuitivo, capaz de fazer escolhas e de se constituir neste movimento. Não é um ser imóvel e fechado, totalmente predeterminado por configurações biológicas, sociais, culturais ou cognitivas, mas se constitui como aberto, em devir, no movimento da própria evolução da vida que envolve várias dimensões. Surge aqui, certamente, um dos maiores desafios à educação: como pensar uma educação em relação a um ser que se constitui a partir de uma evolução criadora, que se faz, Número 22: maio - outubro/2014 
a partir de seu campo de possibilidades, em constante devir?

\section{A filosofia bergsoniana e a educação}

Os estudos da filosofia de Bergson em sua relação com a educação vêm ganhando espaço no meio acadêmico em geral, sobretudo nos últimos anos. É sabido que este filósofo francês não escreve diretamente nenhuma obra sobre a temática educacional, mas é também notório que participa ativamente de movimentos educativos na França, chegando a ser inclusive Conselheiro Superior da Educação Pública. Além disso, Bergson exerce influência marcante sobre importantes teóricos da educação: Claparède, Ferrière e Kerschensteiner, entre outros representantes do movimento de educação renovada, na Europa; John Dewey e William James, precursores da Escola Nova na América do Norte (TREVISAN, 1995). A preocupação com a educação está presente em alguns dos mais importantes discursos proferidos por Bergson em importantes eventos internacionais, e posteriormente publicados em determinadas coletâneas, aparecendo também vinculada de modo indireto a alguns de seus prin- cipais textos. Bergson preocupa-se antes em desenvolver algumas ideias do que indicar normas e procedimentos. Por isso sua contribuição educacional coloca-se mais no plano teórico do que prático. De qualquer modo, tal contribuição é riquíssima, conforme é enfatizado por renomados filósofos da educação na atualidade, $e$ vem se tornando cada vez mais manifesta através dos inúmeros estudos consolidados, no mundo em geral $e$ no Brasil em particular, em torno da relação do seu pensamento com a educação. Um dos testemunhos diretos disto, nos últimos anos, foi o Colóquio Internacional Henri Bergson "Há cem anos de A Evolução Criadora", que aconteceu na Universidade do Estado do Rio de Janeiro e reuniu diversos pesquisadores nacionais $e$ internacionais que vêm tomando o pensamento bergsoniano, direta ou indiretamente, como uma das principais fontes de referência para seus trabalhos, não só vinculados ao campo educacional mas a diversos outros campos além do "especificamente filosófico". Com efeito, de acordo com o que assinalaram os organizadores do evento no livro publicado por ocasião do mesmo, Imagens da Número 22: maio - outubro/2014 
imanência - escritos em memória de H. Bergson, este filósofo francês se apresenta como um dos grandes pensadores "para os quais a filosofia não se afirma em oposição à 'nãofilosofia', mas em diálogo com ela. A diversidade $e$ a produtividade dos ecos de sua obra em outros campos que não o filosófico (literatura, artes, física, medicina, antropologia, comunicação) convalidam essa apreciação" (LECERF; BORBA; KOHAN, 2007, p. $15)^{2}$. Em particular, no campo da educação, conforme é destacado na continuidade do texto de introdução ao livro (cujo objetivo principal foi justamente o de destacar a "atualidade de Bergson"), esse congresso pu-

\footnotetext{
${ }^{2}$ Corroborando esta afirmação, um estudo realizado por Sandrelena da Silva Monteiro mostra que, entre os anos de 2005 a 2009, foram defendidos no Brasil, e registradas no banco de dados da CAPES, 143 trabalhos de pós graduação (dissertações de mestrado $e$ teses de doutorado) e 28 artigos publicados no Scielo tendo por base de estudo a obra de Henri Bergson. No contingente de teses e dissertações, encontramos 15 trabalhos defendidos na área de Educação; 10 na área de Psicologia; 48 na de Letras, Estudos Literários, Linguistica e afins; 13 na de Comunicação; 14 na de Teatro, Música e Artes Visuais; 3 na de Saúde; 30 na de Filosofia; 2 na de Ciências da Religião; 1 na de Ciências Sociais; 7 na de História, Memória Social e afins. Tudo isto certamente atesta a contribuição do pensamento de Bergson a diversos campos de conhecimento $e$, ao mesmo tempo, o valor que se tem dado a ele (MONTEIRO, 2010).
}

blicou, através de seus anais, inúmeros trabalhos extremamente significativos relacionados a diversas questões de estudo da teoria e da prática educacionais (LECERF; BORBA; KOHAN, 2007, p. 15 e 16).

A concepção educacional de Bergson mostra-se coerente com sua própria concepção filosófica em geral. Segundo ele, a educação deve estimular a liberdade e a criação, favorecer o desenvolvimento do "élan vital", estar em consonância com a própria vida. Para tanto, ela tem que valorizar e buscar estimular tanto a inteligência quanto a intuição dos alunos por intermédio dos diferentes saberes produzidos continuamente pelo conhecimento humano: desde as artes, a filosofia, a história e os estudos clássicos em geral, até as diversas ciências exatas, principalmente a matemática e a geometria (TREVISAN, 1995; LECERF; BORBA; KOHAN, 2007). A educação para Bergson, neste sentido, não deve ser mero acúmulo de conhecimentos da tradição, mas, ao contrário, promover a renovação e a criatividade. $\mathrm{E}$ isto ele chega a nos falar, referindo-se às crianças, na introdução de La Pensée et le mouvant.

Número 22: maio - outubro/2014 
Em todas as áreas, seja das Letras, seja das Ciências, nosso ensino conservou-se demasiadamente verbal. (...) Como seremos ouvidos? De que modo seremos entendidos? Pois que, a criança é investigadora e inventora, sempre à espreita de novidade, impaciente quanto às regras, enfim, mais próxima da natureza daquilo que o homem cria. (...) Contudo, por mais enciclopédico que seja o programa, aquilo que a criança poderá assimilar de uma ciência acabada reduzir-se-á a poucas coisas e será, muitas vezes, estudado a contragosto e esquecido logo em seguida. (...) Cultivemos antes na criança um saber infantil $e$ evitemos de sufocá-la sob o acúmulo de ramos $e$ folhas secas, produto de vegetações antigas; a planta nova não pede nada, senão o deixá-la crescer (BERGSON, 1991, p. 1326).

De acordo com o filósofo francês, para que a educação não se reverta em um mero meio de transmissão de conteúdos enciclopédicos e pré-estabelecidos e possa tornar-se um instrumento de desenvolvimento da criação e da liberdade, é necessário que ela se converta em um saber dinâmico, que além de possibilitar ao homem o conhecimento, lhe dê força $e$ lhe aponte caminhos para que ele possa bem viver. $\mathrm{E}$, de fato, para que isto se efetive, como mencionamos acima, é essencial o cultivo da intui- ção de forma tão representativa quanto o cultivo da inteligência. Enquanto filósofo e educador, Bergson busca estabelecer uma distinção entre estas duas atividades, enfatizando, todavia, a necessária complementação entre elas no movimento dinâmico da vida da consciência ou do espírito. Como vimos acima, apresenta a inteligência como sendo a faculdade do raciocínio e do cálculo, que nos permite enfocar a realidade de modo fragmentário sob a base de um tempo mecânicomatemático por ela constituído a fim de dominar e manipular a matéria. Diferentemente, descreve a intuição como aquilo que nos permite acompanhar, "simpatizar" com a "duração", tempo vivo que é essência $e$ existência movente, criador e transformador dos seres. Por isto a intuição seria, para Bergson, o meio por excelência de conhecimento da vida em todas as suas manifestações. Haveria aqui, portanto, uma distinção entre inteligência e intuição dada pela função de cada uma: "enquanto a inteligência capta o que é material $e$ morto, a intuição penetra na duração, que é como que a vida de todos os seres" (TREVISAN, 1995, p.17). 
Fundamentando-se numa teoria do conhecimento sustentada numa teoria da vida, Bergson apresenta intuição e inteligência como inseparáveis, sendo que o exercício da primeira é importante inclusive para determinar os limites da segunda (SANTOS PINTO, 2010). Trata-se com isso de despertar e desenvolver no homem o que ele denomina de "bom senso" ("le bon sens") que é definido como "a faculdade de se orientar na vida prática, (...) um certo hábito de permanecer em contato com a vida prática, mesmo sabendo olhar mais longe". Relacionando essa faculdade à educação, Bergson nos diz que:

A educação do bom senso não consistirá pois somente em libertar a inteligência das ideias préfabricadas, mas em desviá-la também das ideias demasiadamente simples, em detê-la no limiar das deduções e das generalizações, enfim em preservá-la de uma confiança demasiadamente grande em si mesma (BERGSON, 1972, p. 360).

É com base na noção de "bom senso" que Bergson propõe o ideal de homem que quer ver ser formado, corroborando uma vez mais o que escrevemos acima sobre a sua concepção pedagógica: "queremos for- mar um homem de espírito aberto, capaz de se desenvolver em várias direções. Queremos que ele esteja munido de conhecimentos indispensáveis e capaz de adquirir outros, que ele aprenda a aprender" (BERGSON, 1972, apud TREVISAN, 1995, p. 141).

Por tudo isto, vemos que a filosofia bergsoniana é uma filosofia que nos coloca dentro de outra possibilidade de compreensão da realidade, coloca-nos como participantes conscientes do processo de evolução da vida em busca da ampliação do nosso potencial de liberdade. Em relação à educação, destaca Constança Marcondes César, no prefácio do livro Bergson e a Educação que as preocupações de Bergson se explicitavam por suas indagações:

A primeira indagação de Bergson é: que tipo de homem pretendemos formar? E sua resposta é clara: como não podemos pré-estabelecer o futuro, esperar que a educação prepare para o futuro é um equívoco; não sabemos como será, para que possamos preparar alguém para enfrentá-lo. Tudo o que podemos fazer é desenvolver a liberdade das pessoas, sua iniciativa e criatividade. Há uma íntima relação entre desenvolvimento da criaNúmero 22: maio - outubro/2014 
tividade e expressão da intuição. $\mathrm{O}$ ato criador surge de uma situação de liberdade; educar é fomentar a libertação, fomentar a liberdade, de modo que o homem se engaje em atos com toda a sua alma. Educar é levar o homem a se expor na sua ação, a criar, através da ação (TREVISAN, 1995, p.9).
Esta concepção nos permite compreender o que foi o ponto de partida e o ponto de chegada de sua obra: a recusa em aceitar o determinismo científico e sua interpretação positivista que muitas vezes negam a liberdade humana.

\section{REFERÊNCIAS}

BERGSON, Henri. Cartas, conferências e outros escritos. São Paulo: Abril Cultural, 1979. (Coleção Os Pensadores)

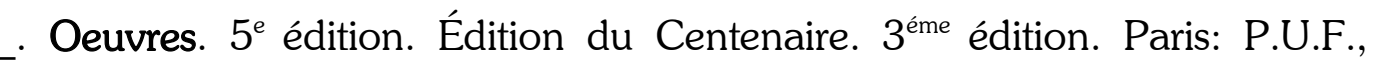
1991.

Mélanges. Paris: P.U.F., 1972.

. A evolução criadora. São Paulo: Martins Fontes, 2005.

. A energia espiritual. São Paulo: Editora WMF Martins Fontes, 2009.

. Matéria e Memória: ensaio sobre a relação do corpo com o espírito. São Paulo: Martins Fontes, 2006.

COELHO, Jonas Gonçalves. Bergson leitor de Lucrécio: as implicações existenciais do determinismo. Trans/Form/Ação, São Paulo, v. 26, p. 129-140, 2003.

LEOPOLDO E SILVA, Franklin. Reflexão e Existência. Discurso, São Paulo, v. 4, $\mathrm{n}^{\circ}$ 4, p. 133-145, 1973.

Bergson: intuição e discurso filosófico. São Paulo: Loyola, 1994.

LOMBARD, Jean. Bergson: création et éducation. Montréal: Harmattan, 1997.

MONTEIRO, Sandrelena da Silva. Contribuições da teoria bergsoniana nas pesquisas em educação: explorando outros mares... Trabalho apresentado como requisito à conclusão da disciplina de "Educação Brasileira: gestão e prática pedagógicas", 
ministrada pela Profa. Dra. Diva Chaves Sarmento, junto ao Programa de PósGraduação em Educação (Doutorado em Educação) da Faculdade de Educação de Universidade Federal de Juiz de Fora (16/11/2010).

MORATO PINTO, Débora; BORBA, Siomara; KOHAN, Walter. Atualidade de Bergson. In:LECERF, Eric; BORBA, Siomara; KOHAN, Walter. Imagens da imanência: escritos em memória de Henri Bergson. Belo Horizonte: Autêntica, 2007. p. 7-25.

PESSANHA, José Américo. Bergson (1859 - 1941): vida e obra. In: BERGSON, Henri. Cartas, conferências e outros escritos. São Paulo: Abril Cultural, 1979. (Coleção Os Pensadores). p. 6 - 14.

SANTOS PINTO, Tarcísio Jorge. O método da intuição em Bergson e a sua dimensão ética e pedagógica. São Paulo: Loyola, 2010.

TREVISAN, Rubens Murílio. Bergson e a Educação. Piracicaba: Editora Unimep, 1995.

VIEILLARD-BARON, Jean-Louis. Compreender Bergson. Petrópolis: Vozes, 2007.

PASCHOAL, Antonio Edmilson. A arte de ler nuances. In: AZEREDO, V. D.; SILVA JÚNIOR, I. (orgs.). Nietzsche e a interpretação. Curitiba; São Paulo: Humanitas, 2012. (Coleção Nietzsche em perspectiva, v. I).

RICCI, Ana Paula. Escolha e seletividade em Nietzsche. Dissertação (mestrado) em Filosofia, Universidade São Judas Tadeu, São Paulo, 2007.

SANTANA, Leila Navarro. Memória: construção sangrenta. Morpheus revista eletrônica. Publicação on-line semestral - ISSN-16 762924.

SILVA, Sérgio Pereira da. Pedagogia do ressentimento: o otimismo nas concepções e nas práticas de ensino. Revista Brasileira de Estudos Pedagógicos, Brasilia, v. 92, n. 230, p. 107-125, jan./abr. 2011. 
VIESENTEINER, Jorge Luiz. O projeto crítico de inversão da compreensibilidade em Nietzsche. In: AZEREDO, V.; SILVA, I. (orgs.). Nietzsche e a interpretação. São Paulo: Humanitas, 2012.

Recebido em 04/11/2013

Aprovado em 19/05/2014 